LAW, ETHICS, AND MEDICINE

\title{
Preimplantation HLA typing: having children to save our loved ones
}

K Devolder

J Med Ethics 2005;31:582-586. doi: 10.1136/jme.2004.010348

Correspondence to:

Katrien Devolder, Ghent

University, Centre for

Environmental Philosophy

and Bioethics,

Blandiinberg 2, B-9000

Gent, Belgium; katrien.

devolder@Ugent.be

Received 17 August 2004

In revised form

17 January 2005

Accepted for publication

17 January 2005

\begin{abstract}
Preimplantation tissue typing has been proposed as a method for creating a tissue matched child that can serve as a haematopoietic stem cell donor to save its sick sibling in need of a stem cell transplant. Despite recent promising results, many people have expressed their disapproval of this method. This paper addresses the main concerns of these critics: the risk of preimplantation genetic diagnosis (PGD) for the child to be born; the intention to have a donor child; the limits that should be placed on what may be done to the donor child, and whether the intended recipient can be someone other than a sibling. The author will show that these concerns do not constitute a sufficient ground to forbid people to use this technique to save not only a sibling, but also any other loved one's life. Finally, the author briefly deals with two alternative scenarios: the creation of a human leukocyte antigen (HLA) matched child as an insurance policy, and the banking of HLA matched embryos.
\end{abstract}

\section{PREIMPLANTATION GENETIC DIAGNOSIS IN CONJUNCTION WITH HLA-TYPING}

Preimplantation genetic diagnosis (PGD) has been used to enable families to have a child that is a tissue match for an existing sick sibling in need of an allogeneic haematopoietic stem cell (HSC) transplantation. HSCs are blood forming cells found in the bone marrow, the peripheral blood, and the umbilical cord blood. For several lethal malignant disorders and also for some non-malignant disorders bone marrow or blood cell transplantations are currently the only therapeutic approach. ${ }^{1}$ The success of a transplant depends on how well the human leukocyte antigen (HLA) types of the donor and recipient match. ${ }^{\mathrm{i}}$

A transplant from an HLA identical sibling is associated with a much higher success rate than a transplant from alternative donors. $^{2}$ Since all humans inherit half of their HLA type from their mother and the other half from their father, each sibling has a one in four chance of being HLA identical to one of his siblings. Given the current size of the average family in Western countries, the chance of having an HLA identical sibling is no more than $15 \%{ }^{3}$

The use of PGD is not a necessary condition for creating "HLA matched donor children". Before the routine use of PGD in assisted reproduction technologies (ART), there had been several cases in which a couple had had one or more children, through natural reproduction or IVF, in the hope that those children or one of them would be an HLA match for an existing child in need of a HSC transplant. Two such cases were the well publicised Ayala case in $1993^{4}$ and the less well known Curry case in 1991. ${ }^{\text {ii }}$ Some sought prenatal diagnosis and were prepared to terminate their pregnancy if the fetus was not a match. ${ }^{5}$

Preimplantantion genetic diagnosis for HLA testing has been proposed as a superior method for creating a tissue matched child that can donate stem cells to its sick sibling. ${ }^{6}$ The main advantage of this method is that it provides genetic information about embryos prior to implantation, so it is possible to ensure that only those embryos that are a tissue match are transferred to the mother's uterus. The couple can thus avoid the difficult decision of either terminating the pregnancy if the fetus is not a match or of extending the family, in the hope that the next child will have the desired HLA type.

In May 2004, a team headed by Anver Kuliev and Yuri Verlinsky, at the Reproductive Genetics Institute of Chicago, reported the birth of five healthy children from five different couples, created to serve as HSC donors for their older siblings affected with leukaemia, or diamond blackfan anaemia (DBA), ${ }^{7}$ a rare form of anaemia where the bone marrow produces few, or no, red blood cells and which results in severe deterioration of normal life sustaining functions. Haematopoietic stem cell transplantation is the only possible cure. Since the leukaemia and the DBA in the affected siblings are sporadic, the matched children were not at risk from the same disease. This means that PGD was used solely for HLA typing, and not as a diagnostic technique to detect genetic diseases, for which it is normally used. One sibling with DBA received transplantation and is no longer dependent on transfusions of red blood cells, whereas the others are in preparation for transplantation or are in remission. $^{7}$

In March, the Belgian team led by Van de Velde reported the development of a new HLA typing technique which Abbreviations: DBA, diamond blackfan anaemia; HLA, human
leukocyte antigen, HSC, haematopoietic stem cell; PGD, preimplantation
genetic diagnosis

'A person's human leukocyte antigen type is determined by her antigen pattern, that is, the markers on the surface of body cells and tissues. They are used by the immune system to distinguish one's own body cells and tissues from foreign ones.

ii In the Curry case a couple in the US had a daughter, Natalie Curry, with Fanconi's anaemia. The couple decided to have another child in the hope that it would be a tissue match for Natalie. The woman became pregnant, but the fetus miscarried. After one month she was pregnant again, and a healthy baby, Audrey, was born. Unfortunately, Audrey was an unsuitable donor. Within 12 weeks the woman was pregnant again. Emily was born healthy and was a match. Twenty months after Emily's birth, cord blood was transplanted into her sister, who was then four years old. Two years later Natalie was cured. ${ }^{4}$ 
would considerably speed up the process of HLA typing. ${ }^{8}$ The sooner a donor match is found, the greater the success rate of the HSC transplant in the sick sibling. The study aimed at conceiving tissue donors for children affected with Bthalassaemia, but the method could potentially be used for other conditions as well where the selection of an HLA identical embryo to create a stem cell donor may be requested, including other types of cancer and other disorders of the blood cell lineage (Verlinsky et al, ${ }^{7}$ p 2082). For a list of diseases treated by HSC transplants see the webpage developed by the Umbilical Cord Blood Education Alliance. ${ }^{9}$

Despite these promising results, however, many people have expressed their disapproval of the use of preimplantation tissue typing to have a child that can save a sick sibling.

I will address some of the main concerns of these critics and show that they do not constitute a sufficient ground to forbid people to use this technique to save the life of either a sibling, or of any other loved one.

\section{THE RISKS OF PGD FOR THE CHILD TO BE BORN}

Preimplantation genetic diagnosis is an established method for the diagnosis of genetic diseases, the aim of which is to prevent the implantation of affected embryos. ${ }^{10}$ Many defenders of PGD for selection against genetic diseases are, however, opposed to PGD solely for HLA typing. They argue that an embryo and the person it will become should be exposed to the risks of PGD only if the embryo/that person is likely to derive enough benefit to outweigh these risks. ${ }^{11}$ These risks are the as yet unknown long term effects of PGD resulting from the extraction of one or two cells from the early embryo. The underlying reasoning is that when PGD is used to test for genetic diseases that testing is done in the best interests of the embryo or the person it will become, whereas when PGD is used solely for tissue typing, the only benefit is for the existing sick child. Before the recent extension of the UK Human Fertilisation and Embryology Authority's policy on tissue typing, ${ }^{12}$ the HFEA's chair, Suzi Leather, formulated it as follows: "PGD can secure an outcome, which is much better than the horrible death say, of an infant with Tay Sachs condition. Clearly then the resulting child benefits from the PGD to the extent that it owes its serious-disorder-free life to PGD [author's italics]. But an intervention which imposes risks without benefits, or where the benefits accrue to another person, is very different."13

This way of stating the objection is problematic. It is misleading to say that the child owes its "serious-disorderfree" life to PGD. The child without Tay Sachs owes its life to PGD, in the same way as any other child selected following PGD for whatever reason owes its life to PGD. It is not as if the same child without PGD would have been affected by the disease. Preimplantation genetic diagnosis is not a cure, it is a selection procedure. An embryo is selected because of genetic characteristics it already had. ${ }^{14}$

How then can PGD benefit children resulting from this procedure? For those who believe it is better to exist than not to exist (except if your life is so bad that it is not worth living), the only conceivable benefit of PGD for the resulting child is its existence, rather than a "serious-disorder-free" existence. Without PGD it would probably not have existed at all. The parents would not have had this particular child. For those who do not believe existence is a benefit, none of the children who have come into the world after PGD have directly benefited from PGD. Consequently, regardless of whether you think coming into existence is a benefit or not, PGD does not benefit the child in the sense that it prevents the child from having a serious disease. The argument expressed by Suzi Leather does not hold good.

Will the resulting child be harmed by PGD? We could say that one part of the procedure-the extraction of the cells-might harm the child, but PGD as a whole might nevertheless not harm the child if it was a necessary condition for the child's existence. This does not mean that the child could not have a complaint about the procedure. However, a child resulting from PGD for tissue typing has no more grounds for complaint about possible side effects than a child resulting from PGD for diagnosis of a genetic disease, given that in both cases PGD was a necessary condition for the children to exist. This has an important implication.

In the case of PGD for HLA typing, PGD is carried out for a clearly person affecting reason, namely saving an existing person-the sick sibling - whereas in the case of PGD for the selection against genetic disease, PGD is carried out for a mainly non-person affecting reason, namely the creation of a new person without a genetic disease as opposed to the creation of another new person with a genetic disease. (See the non-identity problem developed by Derek Parfit. ${ }^{15}$ ) Of course we could say there will also be person affecting reasons for the latter-namely to benefit parents and society-but these kinds of person affecting reasons might also operate in the former case. The important point is that in the case of PGD for HLA typing there is an extra sort of person affecting reason for doing PGD, namely to save the sick child. ${ }^{\text {iii }}$

In my opinion, this makes the moral case for PGD for HLA typing even stronger than the moral case for PGD for selection against genetic diseases.

If one accepts the possible risks of PGD for the benefit of people who want a child, one should certainly accept these risks for the benefit of parents who want a child and for the benefit of a sick child in need of a transplant.

In both cases, however, we should only go ahead with the procedure if we think the health risks are minimal. It seems incoherent to me to treat a sick, suffering child by bringing new suffering into the world. The crucial question is what amount of suffering we can risk inflicting on one person to alleviate the suffering of another person. One strategy, and I think this is a very reasonable one, is to look at what is generally accepted in society, that is, the risk we accept now in sexual reproduction. Since the introduction of PGD in 1990 more than 1000 children have been born as a result of the procedure. ${ }^{16}$ Current studies indicate that embryo biopsy does not increase the incidence of major malformations in the children compared to IVF or intracytoplasmic sperm injection (ICSI) children, or to figures from population registers. ${ }^{17}$ In order to introduce a control mechanism for risk assessment, families should be encouraged to participate in follow up studies.

\section{THE INTENTION TO HAVE A DONOR CHILD}

It is, however, precisely this person affecting reason that is the main cause for concern for the opponents of preimplantation tissue typing to create a donor child. Richard Nicholson, editor of the Bulletin of Medical Ethics, says: "We are not creating this saviour sibling to be a child in its own right. We have created it-designed it-to be a source of spare parts for an existing child." ${ }^{18}$ Nicholson continues: "Where do we draw a moral distinction between slavery...and creating what I prefer to call slave siblings". ${ }^{18}$ Suzi Leather says we might equally call them "spare part sisters" or "bred to order brothers".

These statements are problematic because they are based on the speculative assumption that donor children, or so called "saviour siblings", are created merely for instrumental reasons - to serve as a donor for the sick sibling — and not for their own sake. It has been argued many times before that this line of reasoning does not hold good. ${ }^{3} 20$

iiiThanks to Nick Bostrom for very helpful feedback. 
First of all, parents have children for all kinds of instrumental reasons. Results of "The Value of Children Project" (in 1973, before most assisted reproduction techniques were developed), coordinated by James Fawcett, indicated that one of the advantages of childbearing most frequently mentioned is the benefit for the husband wife relationship. Other frequently mentioned reasons include "immortality" of the individual, continuity of the family name, and the economic and psychological benefits children provide when their parents become old. ${ }^{21}$ This is not considered to be problematic, as long as the child is also valued in its own right.

What does it mean, however, to be valued in your own right? (If you are extremely rich or talented, and people approach you because of these characteristics, does that mean they do not value you in your own right?). Suppose we express it differently, and situate the problem not in the vagueness of not being valued in your own right, but rather in terms of not being respected, loved, or taken care of in the way people expect in given circumstances. Consider, for example, adoption. It is generally expected-at least, in theses times and in certain cultures - that when you make a child, you should accept that it is your responsibility to raise and educate it. (This is the basis of the "welfare of the child assessment" in ART prescribed by the HFEA act ${ }^{22}$ ). In the Netherlands, more than 70 children are put up for adoption every year, and the rate is still increasing. Since the adoption law came into force (1954) approximately 25000 Dutch children have been adopted out. The Dutch Birthmother Foundation serves the interests of Dutch birthmothers and aims at "breaking through the social prejudices involved in giving up a child, discussing the alternatives to giving up a child, bringing birthmothers into contact with each other and giving them support, influencing the development of policy on adopting as well as giving up a child and expressing solidarity with birthmothers in other countries". ${ }^{23}$ From an American site for birthmothers we learn that "there are many reasons why Birthparents choose adoption: a single mother may want her baby to have two stable parents, a couple may feel they're too young or don't have the financial resources to raise a child. Others need to complete their education or are in the midst of career difficulties. Even married birthparents may feel their relationship is not stable enough for a child or they cannot care for more children." ${ }^{24}$ It is even stated on the site that "Birthmothers are the generous women who have made a choice that will enrich a child's life and bless adopting parents with the ultimate gift of life-to be able to parent".

These claims may not represent the general opinion in society, but they show us that in human reproduction there is always a risk of abandonment. Moreover, the fact that support is provided for these birthparents, instead of-for example, punishment via imprisonment or fines, shows we think that children put up for adoption do not face prospects so awful that we should do everything we can to prevent that children will be abandoned. If we accept that there is a risk of abandonment in human reproduction, why should we forbid people to have a child to save their pre-existing child because of the risk of "instrumentalisation" and/or abandonment?

One argument could be that the risk of abandonment would be much higher in the case of donor children because there is a difference in intention when having these children. The reasoning then is that, whereas-to continue the adoption analogy-having a child by accident and adopting it out is acceptable, the creation of a child with the intention to use its stem cells and then to adopt it out, is something very different, and ethically unacceptable. Many opponents of preimplantation HLA typing argue that although the harvesting of haematopoietic stem cells from children is acceptable, it is wrong to create a child with this intention. For some this is a sufficient argument to forbid preimplantation tissue typing in order to have a donor child. Others are of the opinion that the creation of a donor child is acceptable only if the parents wanted another child anyway: they need to have a "genuine desire to have a child"; their intention to have a child should be clearly separated from the later "use" of the child. ${ }^{25}$ My response to this is that first of all, these people seem to forget that plans to have children typically change according to the circumstances and experiences of childrearing. Secondly, it is extremely difficult, if not impossible, to separate the reasons that lead to the conception of a child because of a "genuine desire for a child" from those linked to an attempt to save another child. Moreover, these critics mistakenly presuppose that the desire or the intention to have a child determines the attitudes of the parents toward the child once born. This would imply that children conceived in order to have a brother or sister for an already existing child would not be loved, which, fortunately, is not the case.

If parents were to abandon the child after they had obtained the stem cells, then, of course, it would be clear they had created the child merely for instrumental reasons and this would wrong the child. Firstly, such a scenario is most implausible. The fact that these parents make so much effort to try to save their first child suggests they are caring and loving parents and makes it very unlikely that they will treat the new baby as a "bred to order child". ${ }^{19}$ What is most important in a parent child relationship is the love and care inherent in this relationship. We judge people on their attitudes toward children, rather than on their motives for having them. Anecdotal evidence from the families who have created a child as a tissue donor for their pre-existing sick child indicates that these children receive all the love and care children should get, see-for example, the article by Jablon. ${ }^{26}$ Secondly, as pointed out before, reproduction always involves a risk of abandonment. This is not a reason to stop conceiving children. Moreover, we should always keep in mind that the potential benefits for the sick child are enormous, which could well compensate for the risks to the future child, that is to the child to be created.

\section{LIMITS: WHAT CAN BE HARVESTED FROM THE CHILD AND FOR WHOM?}

Two central concerns of opponents of preimplantation tissue typing to create a tissue donor are the limits that should be placed on what may be done to the donor child in order to treat a sibling, and whether the intended recipient can be someone other than a sibling. ${ }^{27}$

In accepting someone as an organ donor the most crucial considerations are the seriousness of the recipient's need, the likelihood of avoiding serious complications for the donor, and the quality of the donor's consent. Of course, newborns and small children cannot give autonomous donor consent. To decide what can be done to a child created to serve as a donor we can use what has been called the "postnatal" test (Pennings et al, ${ }^{3}$ ). The standard here employed is what would be acceptable if the donor child already existed. Umbilical cord blood harvest is widely accepted since it entails physical intrusions neither on the newborn child, nor on the mother. There have been discussions about whether early clamping of the umbilical cord can negatively affect the neonate but this has been disproved. ${ }^{28}$ Bone marrow donations from young children to siblings are also widely accepted. Harvesting vital organs from children is not acceptable in view of the risks involved for the donor child. The donation of a kidney constitutes a difficult borderline case, ${ }^{29}$ since one can live a healthy life with one kidney, but, of course, such a life is never without risks. I will not go deeper into the very 
complex discussion of paediatric living organ donation in this paper, but would like to mention that one possible approach is to say that the more risk and inconvenience involved in a procedure, the closer the relationship between donor and recipient should be. A kidney donation between two young siblings would therefore be more justifiable than one between two siblings growing up in different families. The reasoning behind this is that there is a potential psychological benefit for the donor child. A very young child may later on experience gratification or, when it is not allowed to donate stem cells or a kidney, a feeling of guilt. Moreover, if the recipient is-for example, a sibling, the donor child will have the advantage of growing up in a less stressful family environment than if the sick child had died. Decisions about such complex issues should be made on a case by case basis, the costs and potential benefits should be carefully weighed up, and the parents should make the decision with the best interests of their children in mind.

The second concern of opponents of PGD/HLA typing to create a donor child is whether this technique should be available when the intended recipient is someone other than a sibling.

In the Netherlands-for example, a father with leukaemia was saved by his daughter's umbilical cord blood ${ }^{30}$ : Pennings mentions this example. ${ }^{25}$ In the UK, the HFEA stipulates that PGD for HLA typing should not be available if the intended recipient is a parent. ${ }^{31}$ But why not?

One possible argument for banning these techniques when the intended recipient is a parent could be that since the chance of having a tissue matched child is very small ( 1 in 200), the IVF/PGD treatment is futile (given the extremely low chance of a successful pregnancy and having a matched embryo). However, the situation might be more problematic if bone marrow is needed. Umbilical cord blood stem cells need not be as closely matched as bone marrow stem cells. The age, the health status, and the disease of the recipient are also factors that determine how closely the match needs to be. Another possible problem is that the number of stem cells that can be obtained from the cord blood is too small to treat an adult. Research is, however, being directed toward overcoming this restriction in order to extend this option to adult patients. ${ }^{32}$

A second possible argument is that a conflict of interests could endanger the life of the child.

This conflict of interests is also present, however, when the recipient is a sibling. ${ }^{25}$ First of all, in the case where the recipient is a parent, it would meet the postnatal test since bone marrow transplantations from children to their parents are currently accepted. ${ }^{33}$ Secondly, as previously said, it is very unlikely that people who make so much effort to save a sick child or another loved one, will mistreat the new child. Thirdly, in liberal countries, the decision to have children is an area of private life in which the state may only intervene to prevent serious harms. Consequently in such countries if there is no reason to think the future child will be harmed, couples requesting PGD for HLA typing in order to have a donor child should be allowed to seek the necessary treatment.

If we know there is a reasonable chance that if a couple has a baby, stem cells from the cord blood will be used to treat their desperately sick child, or any other person they want to help, I do not see any reason to refuse them PGD/HLA typing to select a matched embryo. The donor child will not be harmed by the procedure and a desperately sick person can be saved. Even when there is a chance that, at a later age, a bone marrow harvest might be needed, this procedure should be allowed. Research has indicated that the levels of pain experienced by bone marrow donors are rather low ${ }^{34}$ and that the discomfort and psychological maladjustment experienced by the donor can be reduced through good monitoring. ${ }^{35} 36$ When the burdens can be kept to a minimum, it should be up to the parents as guardians of their child to decide what can be done to their child in order to save another loved one. It does not matter whether the recipient is family or not. We sometimes have stronger emotional bonds to people unrelated to us than to family members. Therefore, we should not restrict the use of PGD/HLA to siblings, as the HFEA currently does, but instead should allow people to have children to help other loved ones as well their existing children

\section{ALTERNATIVE SCENARIOS Insurance policy}

What should one think of the option of using preimplantation HLA typing to ensure that all of one's children will be HLA identical, in case one of them needs a transplant? This option has been presented by Pennings. ${ }^{25}$

On the basis of considerations related to the risks of PGD and the welfare of the donor child, we have no good reason to object. We already accept the risks of PGD in order to benefit people with the desire for a child, and the child will certainly be created for its own sake, since its use as a donor is only conditional. Creating an HLA matched child as a back up or an insurance policy may, however, be more difficult to justify because of the costs and effort required for the procedure. Preimplantation genetic diagnosis in conjunction with HLA typing is labour intensive and requires multidisciplinary collaboration. ${ }^{37}$ The financial cost is currently very high. If PGD is used to create a child that can save its sibling, then these costs can be compared with the probable higher costs related to the use of unrelated donors or a continued programme of standard medical treatment with no prospect of a cure (Van de Velde, ${ }^{8} \mathrm{p}$ 706). In the case of pre implantation tissue typing to create a back up there is no such weighing up to be done. Once the procedure becomes more routine, however, the effort and costs would be reduced and this option should be reconsidered.

\section{Banking of HLA typed embryos}

A valuable option which might be worth exploring as an alternative to back ups is the banking of HLA typed frozen embryos to provide a wide range of HLA types for unrelated individuals in need of compatible stem cells or tissue. One could adopt the embryo and carry it to term so that an HLA matched child is born, or one could use the embryo in vitro as a source of stem cells. Moreover, this option may be more acceptable for those who accept IVF but oppose therapeutic cloning. ${ }^{38}$

\section{CONCLUSION}

In conclusion, PGD for HLA typing offers the possibility of having a child that can save a sick sibling. This person affecting reason for using the procedure is not a reason to forbid the practice, but, on the contrary, constitutes a strong argument in favour of it. Since there are no indications that donor children will be harmed, and we know that some people will be saved, it would be unethical not to allow this procedure and not to explore its further potentialities. When the burdens are minimal, as is usually the case in cord blood or bone marrow donation, it should be up to the parents to decide whether their children or their future children can act as donors for a loved one. This should not be restricted to siblings and not even to family members. It should be offered to any couples who decide to have a tissue matched baby that can save someone whom they love. 


\section{REFERENCES}

1 Benito Al, Diaz MA, González-Vicent M, et al. Hematopoietic stem cell transplantation using umbilical cord blood progenitors: review of current clinical results. Bone Marrow Transplant 2004;33:675-90.

2 Orofino MG, Argiolu F, Sanna MA, et al. Fetal HLA typing in $\beta$ thalassaemia: implications for haematopoietic stem cell transplantation. Lancet 2003:362:41-2.

3 Pennings G, Schots R, Liebaers I. Ethical considerations on preimplantation genetic diagnosis for HLA typing to match a future child as a donor of haematopoietic stem cells to a sibling. Hum Reprod 2002;17:534-8.

4 Anon. When one body can save another. TIME, 1992 Jun 17:54.

5 Auerbach AD. Umbilical cord blood transplants for genetic disease. Diagnostic and ethical issues in foetal studies. Blood Cells 1994;20:303-9.

6 Verlinsky Y, Rechitsky S, Schoolcraft W, et al. Preimplantation diagnosis fo Fanconi anemia combined with HLA matching. JAMA 2001;285:3130-3

7 Verlinsky Y, Rechitsky S, Sharapova T, et al. Preimplantation HLA testing. JAMA 2004:291:2079-85.

8 Van de Velde H, Georgiou I, De Rycke M, et al. Novel universal approach for preimplantation genetic diagnosis of $\beta$-thalassaemia in combination with HLA matching of embryos. Hum Reprod 2004; 19:700-8.

9 Umbilical Cord Blood Education Alliance. http:// www.parentsguidecordblood.com/diseases.html (accessed 10 Jun 2004)

10 European Society of Human Reproduction and Embryology (ESHRE): PGD Consortium Steering Committee. ESHRE Preimplantation Consortium: data collection III (May 2001). Hum Reprod 2002;17:233-46.

11 Wolf SM, Kahn JP, Wagner JE. Using preimplantation genetic diagnosis to create a stem cell donor: issues, guidelines and limits. J Law Med Ethics 2003;31:327-39.

12 Human Fertilisation and Embryology Authority. HFEA agrees to extend policy on tissue typing (press release archive): 21 Jul 2004. http:// www.hfea.gov.uk/PressOffice/Archive/1090427358 (accessed 5 Aug 2004)

13 Leather S. Saviour siblings. Is it right to create a tissue donor baby? London Progress Educational Trust, 2003. http://www.progress.org.uk/Events/ PastEventsSSL.html (accessed 24 Aug 2004).

14 Sheldon S, Wilkinson S. "Saviour siblings": Hashmi and Whitaker. An unjustifiable and misguided distinction. http://www.prochoiceforum.org.uk/ irl_rep_tech_2.asp (accessed 25 Jul 2004)

15 Parfit D. Reasons and persons. Oxford: Oxford University Press, 1984.

16 Verlinsky Y, Kuliev A. Current status of preimplantation diagnosis for single gene disorders. RBM Online 2003;7:145-50.

17 Liebaers I. Outcome of pregnancy and children follow up. In: Belgian Faculties of Medicine, eds. Programme of the symposium: PGD in 2003, A Genetic Odyssey. Ten years of preimplantation genetic diagnosis at the Brussels Free University (AZ-VUB); 2003 Dec 5-6; Brussels, Belgium: 14.

18 Nicholson R. Saviour siblings: is it right to create a tissue donor baby? London: Progress Educational Trust, 2003. http://www.progress.org.uk/ Events/PastEventsSSL.html (accessed 24 Aug 2004)

19 Boyle R, Savulescu J. Ethics of using preimplantation genetic diagnosis to select a stem cell donor for an existing person. BMJ 2001;323:1240-3.

20 Robertson JA, Kahn J, Wagner J. Conception to obtain hematopoietic stem cells. Hastings Cent Rep 2002;32:34-40.
21 Fawcett JT, Arnold FS. The value of children: theory and method. Represent Res Soc Psychol 1973;4:23-36.

22 Human Fertilisation and Embryology Authority. Code of practice [6th ed]. London: HFEA 2003: part 3: 29-35.

23 Dutch Birthmother Foundation. http://www.afstandsmoeders.nl/ (accessed 24 Aug 2004)

24 Adoption Network Law Center. http://www.adoptionnetwork.com/ birthmother-unplanned-pregnancy/adoption-frequently-askedquestions.shtml (accessed 24 Aug 2004).

25 Pennings G. Saviour siblings: using preimplantation genetic diagnosis for tissue typing. Int Congr Ser 2004; 1266:31 1-17.

26 Jablon R. Californian woman marks anniversary of miracles. South Coast Today. http://204.27.188.70/daily/06-96/06-05-96/a02wn014.htm (accessed 5 May 2004)

27 Human Fertilisation and Embryology Authority. Report: preimplantation tissue typing, http://www.hfea.gov.uk/AboutHFEA/HFEAPolicy/ Preimplantationtissuetyping/PreimplantationReport.pdf (accessed $15 \mathrm{Oct}$ 2004).

28 Burgio GR, Locatelli F. Transplant of bone marrow and cord blood hematopoietic stem cells in pediatric practice, revisited according to the fundamental principles of bioethics. Bone Marrow Transplant 1997;19:1163-8.

29 Shenfield F, Pennings G, Devroey $P$, et al. Taskforce 5: preimplantation genetic diagnosis. Hum Reprod 2003;18:649-51.

30 De Greef $\mathbf{P}$. Baby redt leven vader met bloed vit navelstreng (Baby saves life of father with cord blood). De Volkskrant, 2001 Oct 9 2001:1.

31 Human Fertilisation and Embryology Authority. HFEA confirms that HLA tissue typing may only take place when preimplantation genetic diagnosis is required to avoid a serious genetic disorder (HFEA press release office): 1 Aug 2002. http://www.hfea.gov.uk/PressOffice/Archive/43573563 (accessed 24 Aug 2004).

32 Leukaemia Research Fund. Campbell K, series author. Bone marrow and peripheral blood stem cell transplantation. London: Leukaemia Research Fund, 2001.

33 Heiney SP, Bryant LH, Godder K, et al. Preparing children to be bone marrow donors. Oncol Nurs Forum 2002;29:1485-9.

34 Fortanier C, Kuentz M, Sutton L, et al. Normal donor experience. Healthy sibling donor anxiety and pain during bone marrow or peripheral blood stem cell harvesting for allogeneic transplantation: results of a randomised study, Bone Marrow Transplant 2002;29: 145-9.

35 Packman WL. Psychosocial impact of pediatric BMT on siblings. Bone Marrow Transplant 1999;24:701-6.

36 Shama WI. The experience and preparation of pediatric sibling bone marrow donors. Soc Work Health Care 1998;27:89-99.

37 Botkin JR. Ethical issues and practical problems in preimplantation genetic diagnosis. J Law Med Ethics 1998;26:17-28.

38 Barclay L. Preimplantation HLA typing: a newsmaker interview with Anver Kuliev. Medscape Medical News, 2004. http://www.medscape.com/ viewarticle/475082_print (accessed 10 Jun 2004).

\section{Notice}

Ethical aspects of the new genetics: what we all need to know

This one day conference and debate is open to all and will take place at the Cheltenham Town Hall on Friday 18 November 2005

Tickets are $£ 10$ and are available from Gloucestershire Federation of WI's, 2 Brunswick Square, GL1 1UL, tel: 01452523 966; email: Liz@gfwi.org.uk. For futher information visit www.gfwi.org.uk

A limited number of free tickets funded by the Institute of Medical Ethics are available to health care students. Apply with staff confirmation of student status by sending a SAE to Maureen Bannatyne, Insitute of Medical Ethics, St Chloe, The Avenue, Old Bussage, Glos GL6 8AT. 